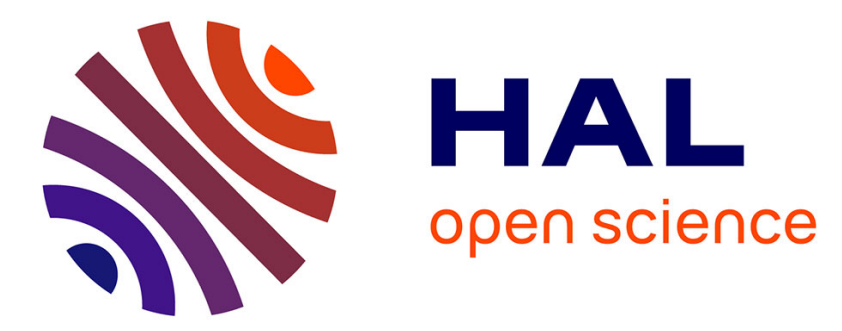

\title{
Surface breaking crack influence on contact conditions. role of interfacial crack friction. theoretical and experimental analysis
}

\author{
Marie-Christine Baietto, Thami Zeghloul, Bernard Villechaise
}

\section{To cite this version:}

Marie-Christine Baietto, Thami Zeghloul, Bernard Villechaise. Surface breaking crack influence on contact conditions. role of interfacial crack friction. theoretical and experimental analysis. Science direct, 1994, 27 (C), pp.345-357. 10.1016/S0167-8922(08)70322-5 . hal-01951921

\author{
HAL Id: hal-01951921 \\ https://hal.science/hal-01951921
}

Submitted on 6 Jul 2021

HAL is a multi-disciplinary open access archive for the deposit and dissemination of scientific research documents, whether they are published or not. The documents may come from teaching and research institutions in France or abroad, or from public or private research centers.
L'archive ouverte pluridisciplinaire HAL, est destinée au dépôt et à la diffusion de documents scientifiques de niveau recherche, publiés ou non, émanant des établissements d'enseignement et de recherche français ou étrangers, des laboratoires publics ou privés. 


\title{
SURFACE BREAKING CRACK INFLUENCE ON CONTACT CONDITIONS. ROLE OF INTERFACIAL CRACK FRICTION. THEORETICAL AND EXPERIMENTAL ANALYSIS
}

\author{
M.C. DUBOURG* ,T. ZEGHLOUL ${ }^{\star \star}$, B. VILLECHAISE* * \\ * Laboratoire de Mécanique des Contacts, URA CNRS 856, INSA, 20 Av. A. Einstein, Bât. 113, 69621 \\ Villeurbanne Cédex, France. \\ ** Laboratoire de Mécanique des Solides, URA CNRS 861, Université de Poitiers, 861 Av. du Recteur Pineau, \\ 86022 Poitiers Cédex, France
}

\begin{abstract}
Numerous studies are devoted to the determination of two body contact conditions, i.e the contact area, the stick and slip zone repartition, the normal and tangential pressure distributions. Interfacial roughness, friction, worn profiles for instance are taking into account as they disturb the hertzian stress field, but no specific attention is paid to the influence of surface breaking cracks. The mutual influence of surface breaking cracks on two body rolling contact conditions was studied theoreticalyy in a previous paper by Dubourg and Kalker [1]. Significative overpressure relatively to the classical maximum hertzian pressure and split up of the contact area were obtained numerically. An original experimental simulation is undertaken to validate these results.

The theoretical model is the combination of a two body rolling contact model and a fatigue crack model. The steady rolling contact between the wheel and the rail is solved as a unilateral contact problem with friction. Displacement and stress expressions derive from Boussinesq and Cerruti potentials. The fatigue crack model is based on distributions of dislocations for crack modelling and unilateral contact analysis with friction for the contact solution between crack faces. These two problems are solved in turn as displacements generated by cracks modify the two body surface geometry. This process goes on until convergence is reached, i.e when the two body contact conditions are stabilised from one iteration to the next.

The experimental work is based on photoelastic technique. Birefringent slabs for both wheel and the cracked rail are employed. Isochromatic fields, normal and tangential loads and global displacements are recorded continuously during the loading. Visualization and calculation of pressure peaks in the wheel and extent of the contact area are performed.
\end{abstract}

\section{INTRODUCTION}

In a previous theoretical study [1] the mutual influence of surface breaking cracks on the wheel-rail contact conditions was investigated. Modifications of the traction distributions with and without split up of the contact area were determined, depending on the relative position of the wheel with respect to the cracks. This paper is concerned with the experimental validation of these results. The experimental part includes the simulation of the contacting movement of the wheel relatively to the cracked rail with vizualisation through photoelasticity technique of the isochromatic fields in both contacting bodies. Theoretical simulation of this experiment will be conducted simultaneously.

\section{THEORETICAL APPROACH}

A steady contact model and a fatigue crack model including frictional locking at crack interface are combined. Connection between the two problems is introduced through surface geometry modification caused by displacements generated by cracks. Both models are half analytical and numerical that imply inexpensive computer time and great accuracy. 


\subsection{Two-body contact}

Steady state normal contact of a cylinder (the wheel) over an elastic half-plane (the rail) is considered. Perfectly elastic conditions are considered, the solids are homogeneous and isotropic. A theory of contact is required to predict the shape of the area of contact, the slip and stick zone repartition, the magnitude and distributions of surface tractions, normal and possibly tangential, transmitted accross the interface (cf. figure 1).

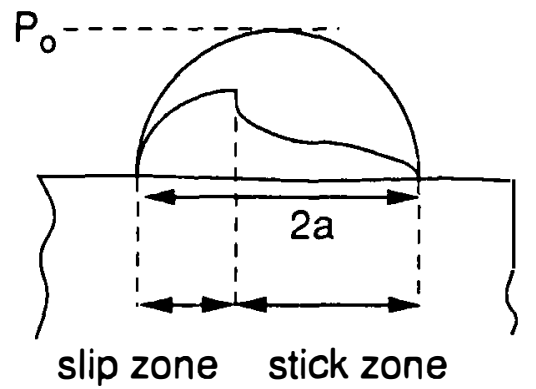

Figure 1 : Wheel/rail contact model

This contact problem is solved as a unilateral contact problem following the method developed by Carneiro Esteves at al. [2]. As semi-infinite bodies are considered, Boussinesq and Cerruti potentials are used. Relations between displacements and stresses are obtained. The potential area of contact is discretized into segments on wich stresses are assumed constant.

\subsection{Crack model}

A theoretical two-dimensional linear elastic model of multiple fatigue cracks was developed $[3,4]$ to determine the stress and displacement fields in cracked solids and the stress intensity factors (SIFs) at crack tips. Multiple interactive cracks, straight or kinked, surface breaking or not, taking into account frictional locking and situated in an isotropic medium can be modelled (cf. figure 2). The model rests on the continuous dislocation theory, pionnered by Keer and Bryant $[5,6]$ and on the unilateral contact theory developed by Kalker [7]. Resultant stress and displacement fields $\left(\sigma^{T}, \delta \mathrm{u}, \delta \mathrm{v}\right)$ are given by superposing the uncracked solid ( $\sigma^{M C}$ ) and the crack $\left(\sigma^{F}, \delta \mathrm{u}, \delta \mathrm{v}\right)$ responses to the load in such a way that $\sigma^{J}$ satisfies the boundary conditions along the faces of the presumed cracks.

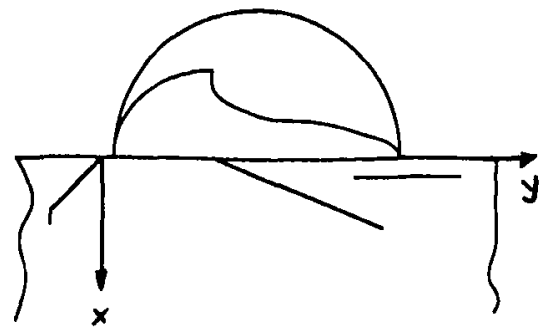

Figure 2 : Fatigue crack model

These boundary conditions (cf. figure 3) are expressed as in a :

- contact zone

$$
\delta u_{n}=0, \sigma_{n n}^{T}<0
$$

- open zone:

$$
\sigma_{n n}^{J}=0, \quad \delta u_{n}>0
$$

- backward slip zone:

- $\sigma_{n t}^{T}=f * \sigma_{n n}^{T} \quad, \quad \delta u_{\imath} * \sigma_{n t}^{T}>0$

- forward slip zone

$$
\sigma_{n t}^{J}=-f * \sigma_{n n}^{J}, \delta u_{t} * \sigma_{n t}^{J}>0
$$

-stick zone

$$
\delta u_{t}=0,\left|\sigma_{n t}^{T}\right|\left\langle f^{*}\left|\sigma_{n n}^{T}\right|\right.
$$

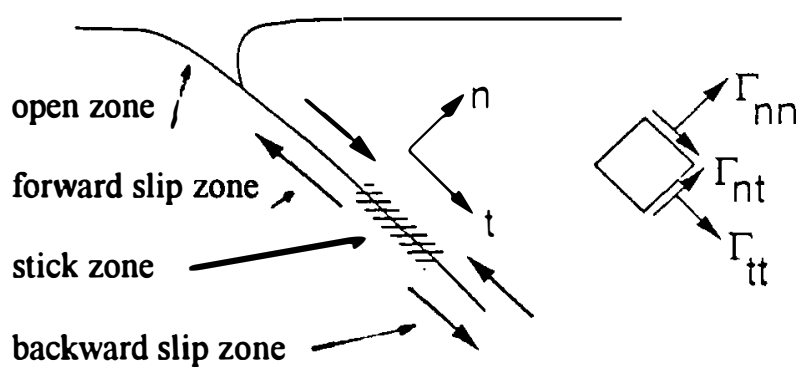

Figure 3 : Boundary conditions at crack interface 
The continuum stress $\sigma^{M C}$ in the uncracked solid may be obtained numerically (finite element analysis for instance) or analytically in the case of a halfplane. The crack response corresponds to displacement discontinuities along its faces, opening and slip, that generate stresses. These displacement zones are modelled with continuous distributions of dislocations bx and by. Single distributions of dislocations bx and by are considered along each crack. It is assumed that by and bx are square root singular at crack tips, and at crack mouths for embedded cracks, bounded elsewhere. The correct behaviour of the stress field along cracks is thus guarantee. The strength of these singularities is then driven numerically to zero in the case of a contact zone or a stick zone at crack tip [3]. Consistent equations come from corresponding boundary conditions $\left(\delta u_{n}=0, \delta u_{t}=0\right)$. This method gives single stress and displacement expressions for the whole crack, independent from the final contact division:

$\sigma_{i j}^{r}=\frac{2 \mu}{\pi(k+1)} \sum_{i=1}^{m}\left(\int_{r_{i}} b_{t r}(\xi) K_{l y}^{x}\left(x, y_{\eta}, \xi\right) d \xi+\int_{\Gamma_{i}} b_{\eta y}(\xi) K_{l y}^{y}\left(x, y_{\eta}, \xi\right) d \xi\right)$

$\mathrm{i}, \mathrm{j}=\mathbf{x , y}$

$$
\begin{aligned}
& \delta u_{t}=\int_{\Gamma_{i}} b_{l x}(\xi) d \xi \\
& \delta u_{n}=\int_{\Gamma_{1}} b_{b y}(\xi) d \xi
\end{aligned}
$$

where $\mu$ is the shear modulus, $k=3-4 v$ for plane strain or $(3-v) /(1+v)$ for plane stress, $v$ the Poisson's ratio, $K_{i j}^{x}, K_{i j}^{y}$ the stress kernels expressed in [3], $\Gamma_{l}$ crack 1 profile, $m$ the number of cracks. Stress expressions are singular integral equations, solved following Erdogan et al [8]. Discretized stress and displacement expressions are obtained. The 2NI unknown are the bx and by values at the discretisation points, where NI is defined by $N I=\sum_{i=1}^{m} p_{i}, p_{i}$ the number of discretisation points

for crack $i$. The contact problem solution between crack faces as a unilateral contact problem with friction gives automatically the contact area division, slip, stick and open zones, and the suitable distributions of dislocations. Load cycles are described with an incremental description which takes into account the load history as hysteresis is generated by friction at crack interface.

This model was used to determine the stress intensity factors experienced at crack tips under various loading conditions, sliding or rolling contact conditions, bulk tractions...

\subsection{Crack influence on two-body contact conditions}

Conditions at interface between the wheel and the rail influence significantly contact stresses. Surface roughness, interfacial friction, worn profiles are taken into account. No specific attention is paid to crack influence.

For convenience of data treatement, the global problem is split into two parts, the two-body contact and the crack problems, which are solved independantly in turn. Connection between the two problems is introduced through surface geometry modification caused by displacements generated by cracks. Note that the displacement field generated by cracks is continuous except along the crack where displacement discontinuities correspond to slip or opening. The normal displacement at the smooth half-plane surface $V_{\text {surf }}$ is calculated at the discretization points of the contact area $2 \mathrm{a}$ from $\mathrm{bx}$ and by. Iterations on crack influence are organized in the following manner (cf. figure 4):

First iteration: the surface geometry considered $\mathrm{H}(\mathrm{y})$ corresponds to a cylinder over a smooth half-plane. The contact problem is solved as exposed in the section II. 1 . The contact area $2 a$ and the normal traction $p(y)$ are determined. The crack behaviour is then determined. Surface displacement $V_{\text {surf }}$ is calculated. $H(y)$ is modified, $h^{\prime}(y)=H(y)+$ relax* V. surf

Next iteration: $h^{\prime}(y)$ is considered as the new profile. The two-body contact is solved again. Continuuum stress field at iteration $j$ is the resultant stress field calculated at the (j-1) iteration. Variations in normal tractions $\delta p$ cause variations in distributions dislocations $\delta b x$ and $\delta b y$. Slip and opening along crack faces are modified and SIFs too. Surface displacement $V_{\text {surf }}$ induces by theses variations is determined again and added to the geometry. This 
process goes on untill convergence is reached, i.e normal tractions exerted on the half-plane surface are stabilized from one iteration to the next. For the next load step, the geometry is reinitiated to $\mathrm{H}(\mathrm{y})$

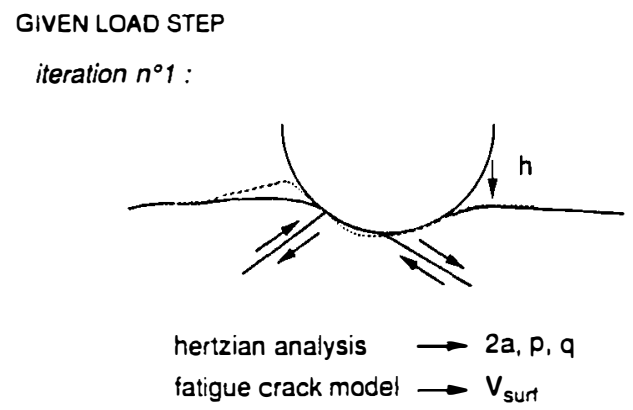

iteration $n \circ j$ :

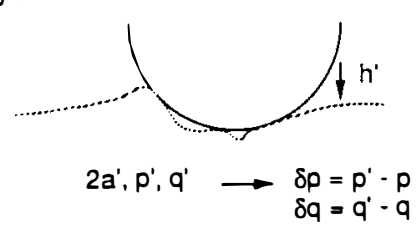

Figure 4: Crack influence on wheel/rail contact conditions.

\section{EXPERIMENTAL APPROACH}

The contact formation and behaviour and particularly in the case of frictional contact is still not yet understood in some cases. A formal definition of the problem particularly in terms of boundary conditions for theoretical modelling is difficult. Understanding frictional phenomena and interactive mechanisms between two body contact and surface breaking cracks on one hand and determing the key parameters on the other hand require an experimental analysis of the contact evolution. The work presented here is concerned with normal contact of a wheel over a cracked rail, and more precisely with the study of the influence of cracks on the contact conditions.

\subsection{Loading frame}

The experimental set-up and both the geometrical and mechanical characteristics of the two contacting bodies are presented on figure 5 . The loading frame is placed in an optical system of photoelasticity. Photoelastic picture acquisition is realised by the use of a CCD camera for numerical treatement. Both wheel and rail scale models are made in polyurethane PSMl of $9.6 \mathrm{~mm}$ width, a birefringent material sold by the Vishay-Micromesures society. The loading frame was realised to ensure the plane stress assumption. The apparatus is made of two parts where the two contacting bodies are fixed. These two parts can move in two perpendicular directions corresponding to normal and tangential loadings. The horizontal guide is realised through two ball columns. The vertical displacement compresses the force sensor $\mathrm{N}$ providing the wheel normal loading. The wheelrail sytem is based on a gas slider. The cracked rail scale model is realised from two trapezoïd reamed parts. These two parts are partially sticked together along their inclined face, forming thus a parallepiped. The unsticked remaining surface corresponds to the crack. The stiffness of the glue, once dry, is identical to those of the polyurethane. This technique guarantees a good geometric definition of the crack.

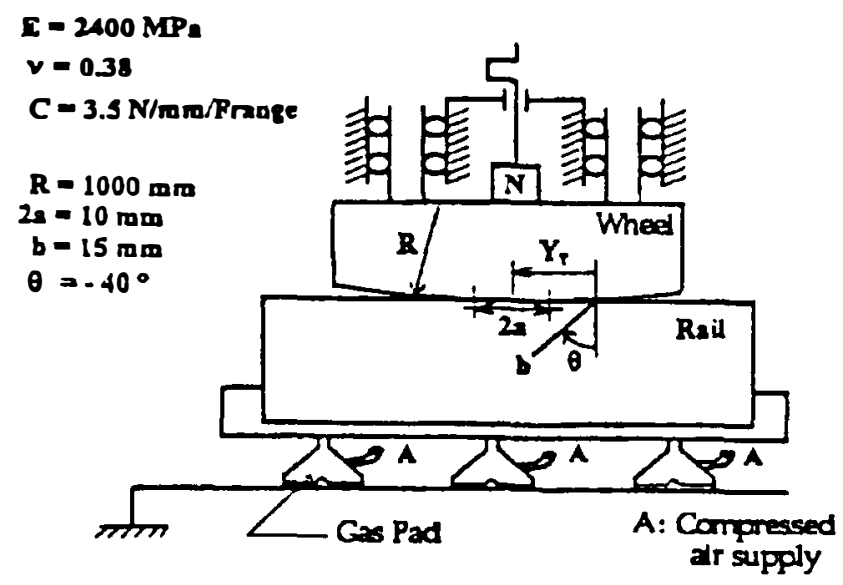

Figure 5: Experimental set-up

\subsection{Tests}

The main goal of the tests realised during this study is to show the influence of a crack on the contact conditions at the wheel/rail interface, i.e changes in the contact conditions during the passage of the wheel over the cracked rail. In this first approach the rotating movement of the wheel is not realised 
experimentally. Only the normal loading is performed. A load step consists in normal loading, unloading and wheel displacement. The running conditions are a normal load of $290 \mathrm{~N}$, a wheel radius of $1 \mathrm{~m}$ that correspond to a contact area $2 \mathrm{a}$ of 10,5 $\mathrm{mm}$. The crack length $b$ is equal to $15 \mathrm{~mm}$ and its inclination is $\theta=-40^{\circ}$. The position of the wheel is defined with respect of the trailing edge of the loading zone $y_{t} \cdot y_{t}$ varies from $-27 \mathrm{~mm}$ to $11 \mathrm{~mm}$ with a $2 \mathrm{~mm}$ displacement increment. 19 load steps are thus realised. The isochromatic field is numerized for each wheel position.

\subsection{Analysis of the isochromatic field evolution}

A phenomenological analysis of the tests was conducted. At $y_{t}=-10 \mathrm{~mm}$ the leading edge of the contact area moves over the crack mouth and at $y_{t}=0$ $\mathrm{mm}$ the trailing edge moves away from crack mouth. Depending on the wheel position several steps were observed:

\section{Step 1: $y_{t} \leq-25 \mathrm{~mm}$}

The normal loading is imposed by a vertical displacement of the wheel. The isochromatic field changes continuously and is slightly disymmetric. This disymmetry is due to a torque associated to macrogeometric difects created at the manufacturing stage of the wheel scale model. During this step, the the wheel is far from the crack and no interacting effect between them is observed.

\section{Step 2: $-23 \mathrm{~mm} \leq \mathrm{y}_{\mathrm{t}} \leq-11 \mathrm{~mm}$}

The wheel rolls nearer the crack; from $y_{t}=9.64 \mathrm{~mm}$ the wheels is above the crack tip. Crack faces are pressed together and sheared. Further stress concentration at crack tip is observed, corresponding to the slip of the left part of the rail. This stress concentration increases when the wheel comes nearer.

\section{Step 3: $-9 \mathrm{~mm} \leq \mathrm{y}_{\mathrm{t}} \leq 3 \mathrm{~mm}$}

The surface breaking crack modifies the contact conditions at the rail surface. The pressure distribution along the contact area is modified locally with split up of the contact area in two parts without modification of its extent Accordingly the numerical model describes in that case both the overpressure and the split up effects. These phenomena are due to the location of the crack mouth inside the contact area.

\section{Step 4: $y_{t} \geq 5 \mathrm{~mm}$}

The wheel moves away from the cracked region which therefore influences no more the wheel-rail contact. The behaviour observed is similar to those described in step 1:

\section{NUMERICAL SIMULATION}

Concerning the two-body contact simulation, a potential contact area of $12 \mathrm{~mm}$ discretized with 121 points is considered. The maximum hertzian pressure Po is equal to $3.67 \mathrm{MPa}$ and the contact area is 10,47 $\mathrm{mm}$ width. The origin of the reference axis is placed at the crack mouth. 30 discretization points are distributed along the crack. Different friction coefficient values were tested, ranging from 0.1 to 0.3 . The best match between theoretical and experimental stress field is obtained for a friction coefficient equal to 0.1 .The relaxation coefficient relax is equal to 0.3 .

For all the load steps the crack behaviour is determined (slip, stick and open zone distribution), the stress intensity factors are calculated (figure ) and the stress fields computed over an area of width 45 $\mathrm{mm}$ along oy and of length $17 \mathrm{~mm}$ over ox. The width is centered with respect to $y=-7.5 \mathrm{~mm}$. The mutual influence of crack on the contact conditions generates:

- stress intensity factor variations,

- pressure distribution modifications with local overpressures,

- contact area width changes,

- split up of the contact area.

\section{Step 1: No significative influence: $y_{t} \leq-11 \mathrm{~mm}$}

No significative mutual influence between crack and the two-body contact is noticed as long as the wheel is not situated over the crack mouth, i.e $y_{t}$ less than -11 $\mathrm{mm}$. At the load step 1 , the the crack is partially open at its mouth, then a forward slip zone holds and the crack tip is sticking. KII is very small $55 \mathrm{~Pa} V \mathrm{~m}$. The state of the crack changes at load step 2: from crack 

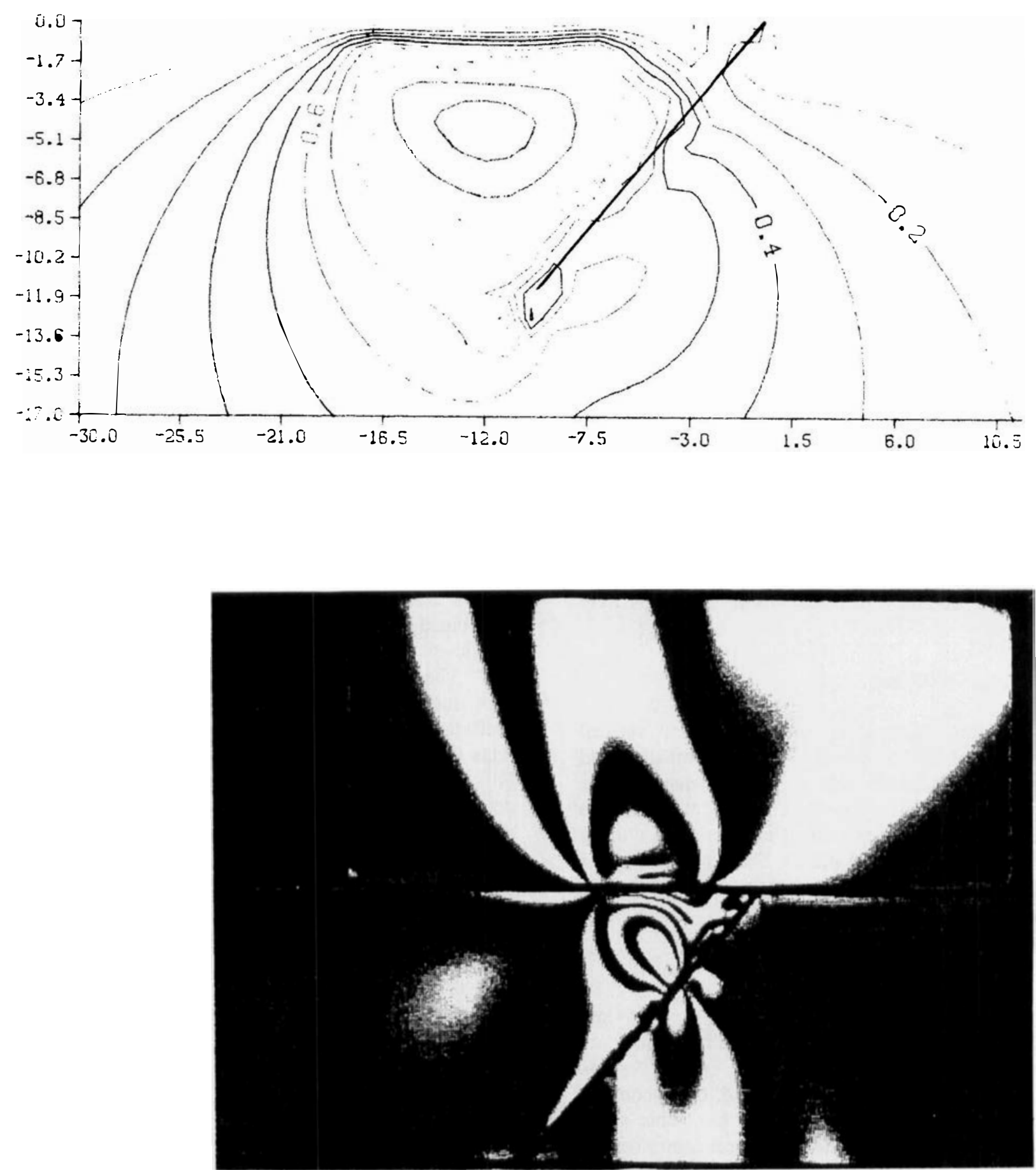

Figure 6 a) : load step $6 y_{T}=-17 \mathrm{~mm}$ 

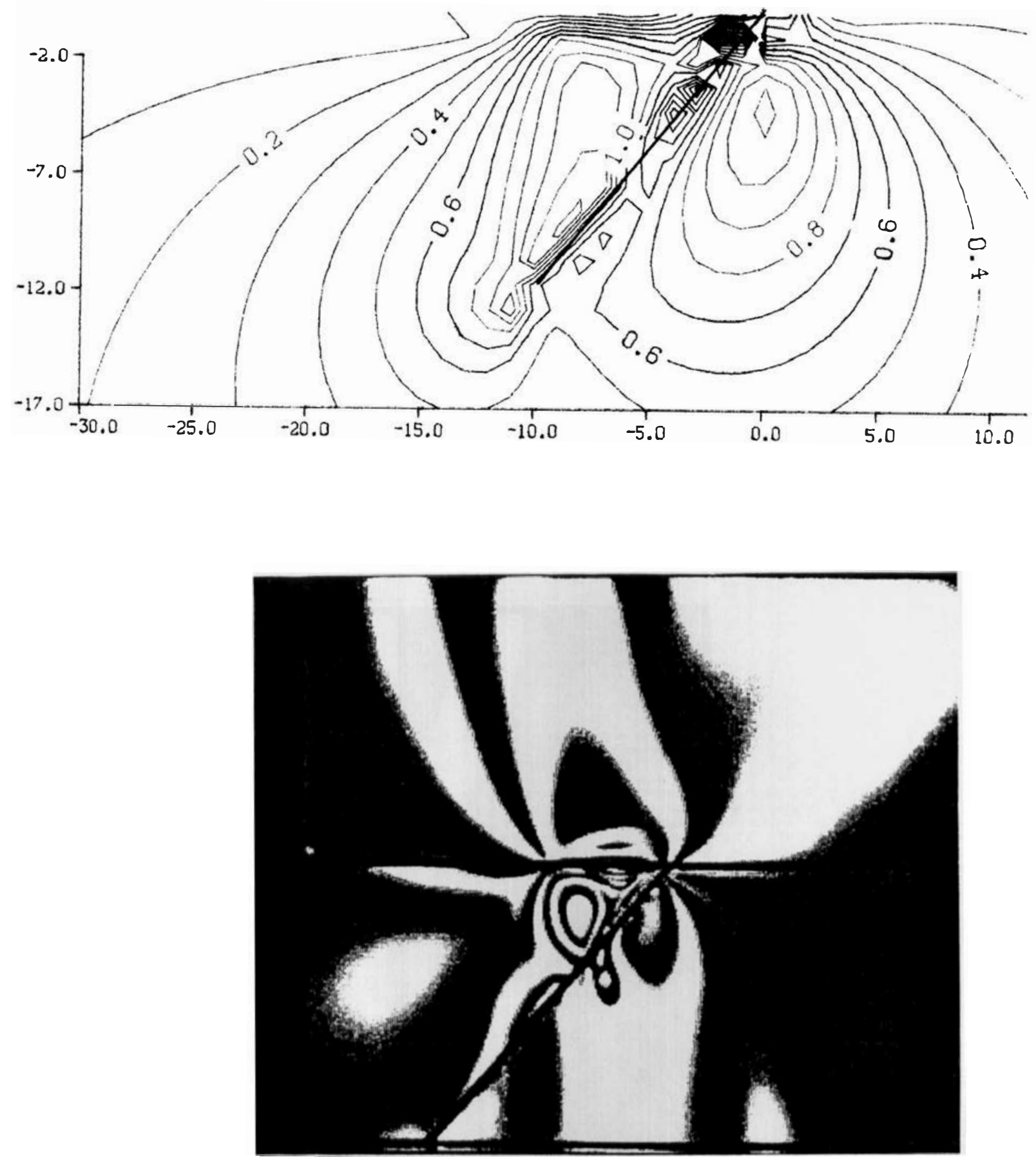

Figure $6 \mathrm{~b}$ ) : load step $9 \quad \mathrm{y}_{\mathrm{T}}=-11 \mathrm{~mm}$ 

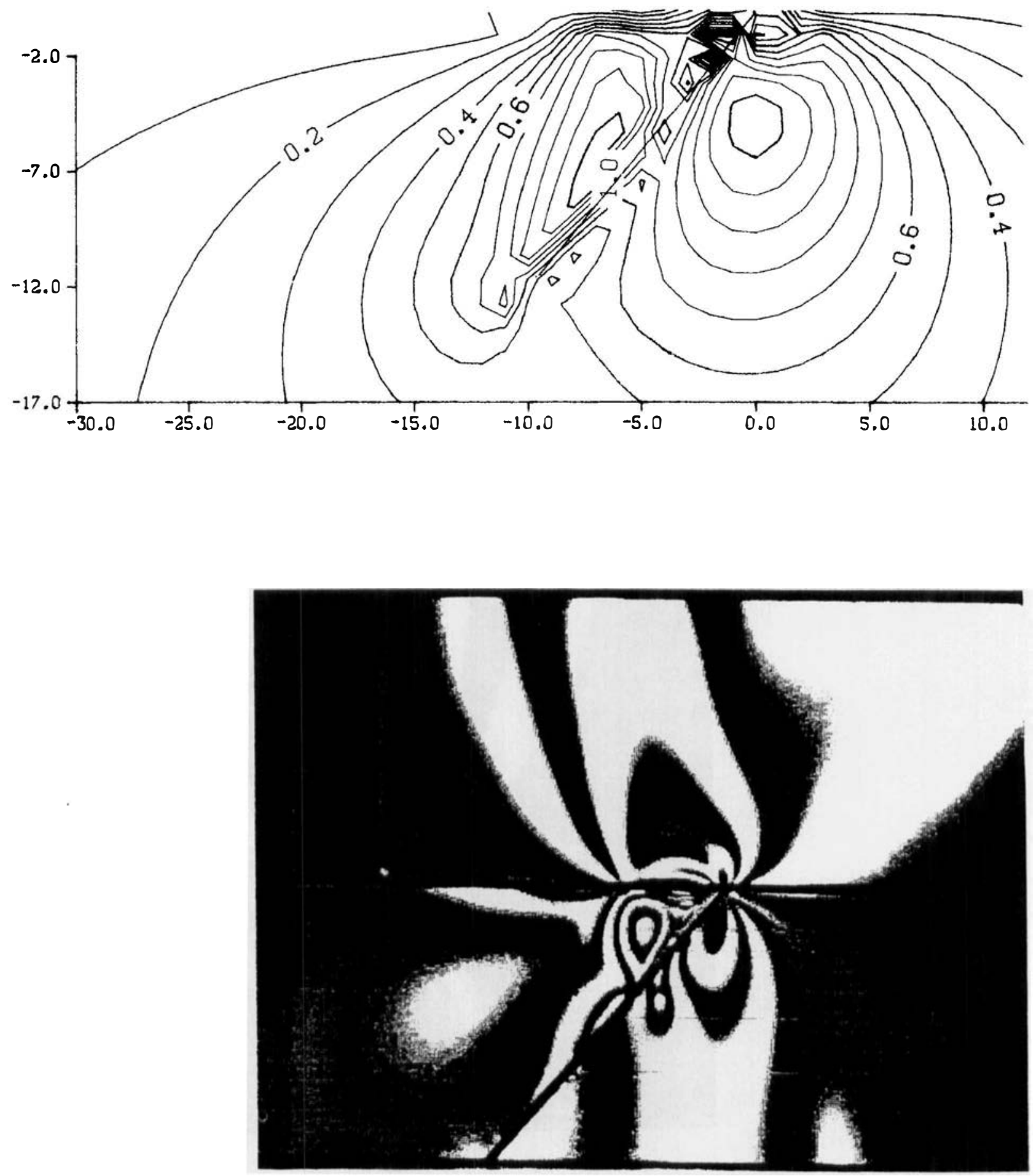

Figure $6 \mathrm{c}$ : load step $10 \quad \mathrm{y}_{\mathrm{T}}=-9 \mathrm{~mm}$

5th coupling iteration 

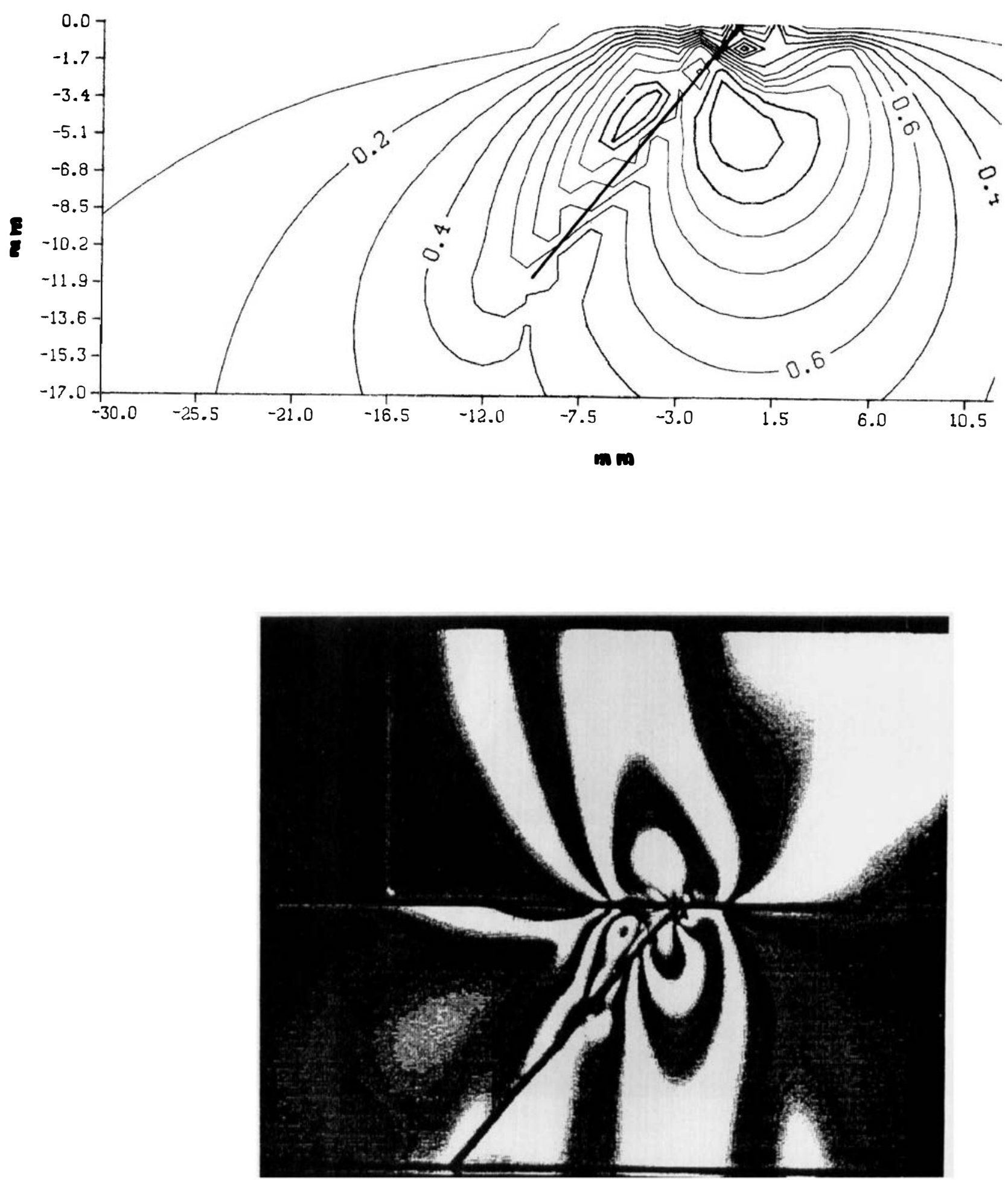

Figure $6 \mathrm{~d}$ ) : load step $12 \quad \mathrm{y}_{\mathrm{T}}=-5 \mathrm{~mm}$ 

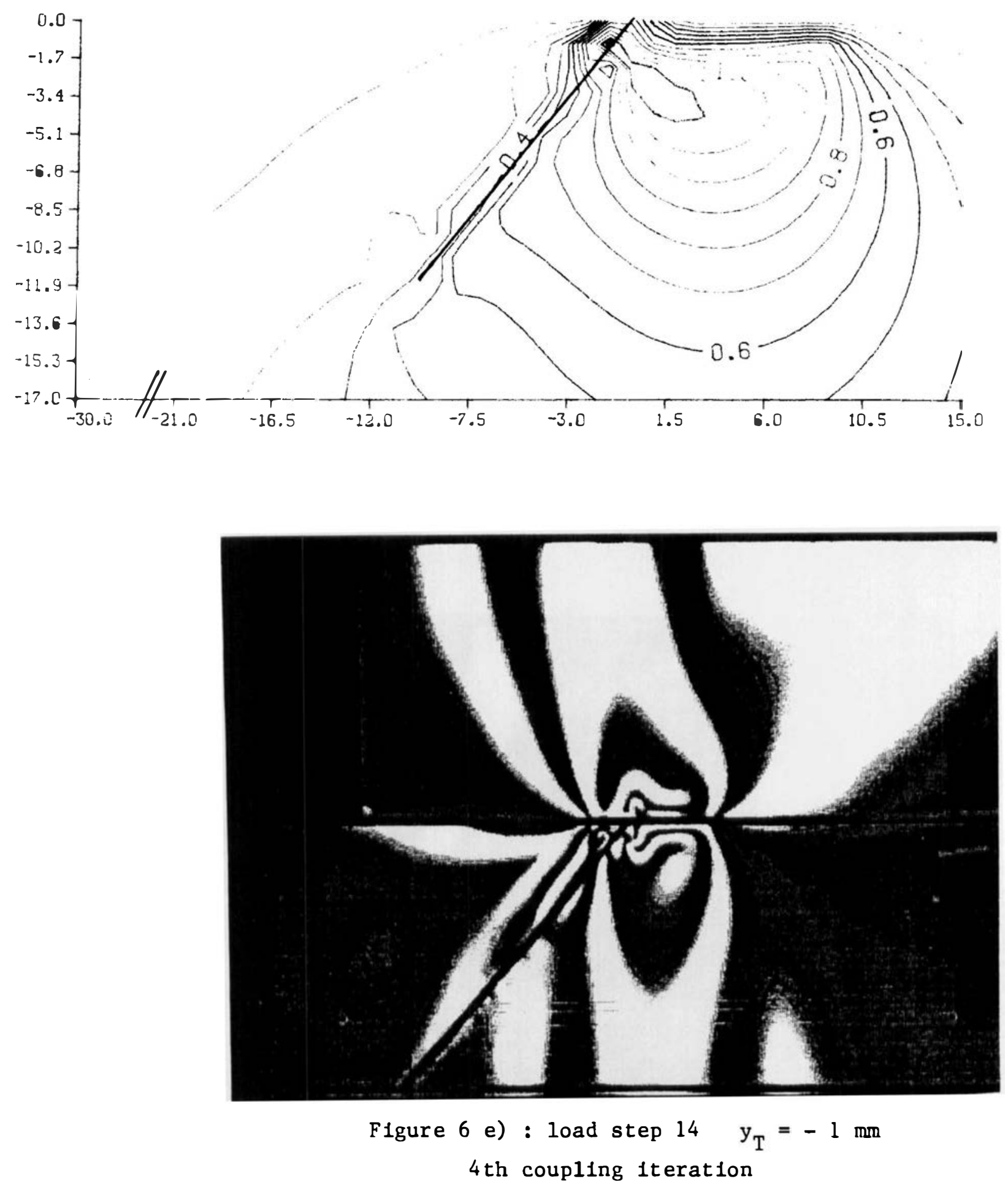

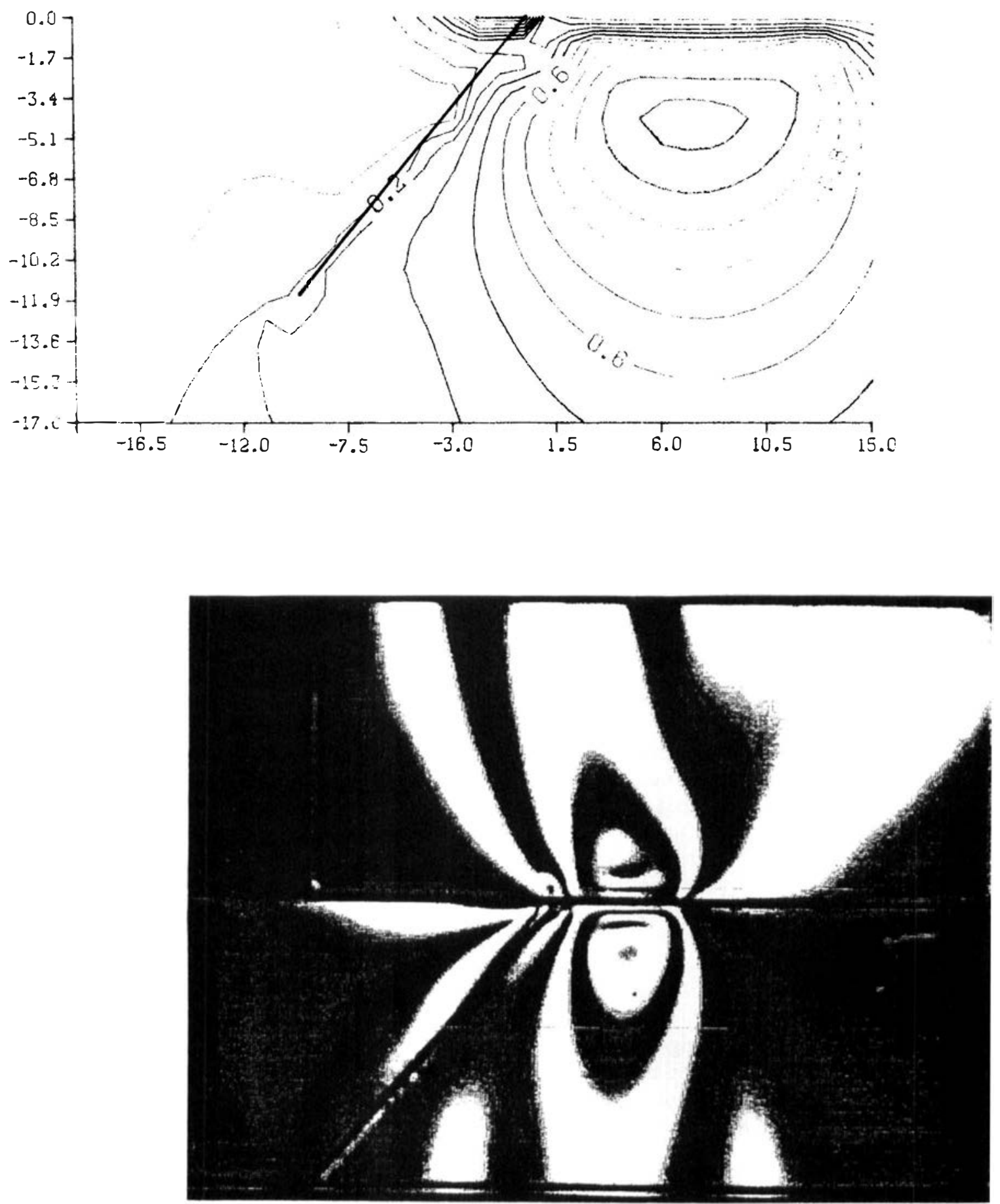

Figure $6 \mathrm{f}$ ) : load step $16 \mathrm{y}_{\mathrm{T}}=3 \mathrm{~mm}$ 
tip to crack mouth a bakward slip zone, a stick zone, a forward slip zone and finally an open zone are distributed. This state doesn't change up to load step 9 included.

\section{Step 2 : Influence: $-9 \mathrm{~mm} \leq \mathrm{y}_{\mathrm{t}} \leq-\mathbf{m m}$}

4 to 5 iterations are needed to converge. Different mechanisms are observed:

$$
\text { -load step 10: } y_{t}=-9 \mathrm{~mm} \text { : }
$$

the leading edge of the contact area is situated over the crack mouth. A global backward slip zone holds along the crack. Coupling leads firstly to split up of the contact area in two parts situated on each side of the crack faces with local overpressures up to 6.8 $\mathrm{MPa}$ and increase in KII from 11250 to $11310 \mathrm{~Pa} \sqrt{\mathrm{m}}$. But at the next iteration the contact area is again in one part, the pressure distribution is very similar to the initial one, and the stress intensity factors too.

$5 \mathrm{~mm}$ :

-load steps 11 and 12: $y_{t}=-7 \mathrm{~mm}$ and $y_{t}=$ -

A particular distribution of displacement zones is observed: the crack is open at crack tip, and a backward slip zone spreads from it up to crack mouth. The compressive action of the two-body loading closes obviously the crack faces at crack mouth. Further the crack tip is situated outside of the compressive zone and therefore an open zone holds there. Coupling leads for load step 11 to overpressure up to $4.49 \mathrm{MPa}$, i.e a $22 \%$ increasing without modification of the contact area width. For the load step 12 , overpressure up to $4.7 \mathrm{MPa}$, i.e a $28 \%$ increasing is noted. For both load steps, KII variations are very small, less than $1 \%$.

-load step 13: coupling is negligible

-load step 14: $y_{t}=-1 \mathrm{~mm}$

A global fonward slip zone holds along the crack. A sligth increasing in the maximum pressure is noted, from 3,67 to $3,69 \mathrm{MPa}$. But split up of the contact area in two parts is obtained: from -1 to to $0.05 \mathrm{~mm}$ and from 0.15 to $9.7 \mathrm{~mm}$.

\section{Step 3: No more influence: $y_{t} \geq 1 \mathrm{~mm}$}

An open zone spreads out from the crack mouth, then a forward slip zone at crack tip.

\section{COMPARISON}

A qualitative comparison is performed between the experimental and the theoretical results. It is based on

- mainly on informations concerning the two-body contact conditions and their modifications due to the crack influence. Split up of the contact area is observed for $y_{t}$ varying from -9 to $3 \mathrm{~mm}$. This behaviour is numerically obtained for $y_{t}=$ $1 \mathrm{~mm}$.

- experimental and theoretical isochromatic fields, presented for load steps 6, 9, 10, 12, 14, 16 (cf. figure 6). They are very much alike.

\section{CONCLUSION}

The influence of surface breaking cracks on two-body rolling contact conditions was previously studied theoretically by one of the authors. Significative overpressure relatively to the maximum hertzian pressure and slip up of the contact area were obtained numerically. An original experimental simulation was undertaken to validate these results. This experimental work is based on the photoelastic technique. Comparison between isochromatic fields and computed stress fields, experimental and theretical two-body contact behaviour (slip up of the contact area) confirms the previous results.

\section{REFERENCES}

1 M.C. Dubourg, J.J. Kalker. Crack behaviour under rolling contact fatigue. In "Rail quality and maintenance for modern railway operation". Proceedings of the International Conference on "Rail quality and maintenance for modern railway operation", Delft (NL), June 1992, Ed. by J.J Kalker, D.F. Cannon, O. Orringer, Kluwer Academic Publishers, p. 373-384, 1993.

2 A. Carneiro Esteves, J. Seabra, D. Berthe. Roughness frequency analysis and particle depth. In Interface dynamics, Proceedings of the 14ème Leeds-Lyon Symposium, 8-11 Sept. 1987. Ed. by D. Downson, C.M. Taylor, M. Godet, D. Berthe. Amsterdam: Elsevier, p 209213, 1988.

3 M.C. Dubourg, B. Villechaise. Analysis of multiple fatigue cracks - Part I: theory. ASME, 
Journal of Tribology, Vol 114, pp. 455-461, 1992.

4 M.C. Dubourg, B. Villechaise, M. Godet. Analysis of multiple fatigue cracks - Part II: results. ASME, Journal of Tribology, Vol 114, pp. $462-468,1992$.

5 L.M. Keer, M.D. Bryant and Hiratos G.K. Subsurface and surface cracking due to hertzian contact. ASME, Journal of lubrication technology, Vol. 104, , pp. 347-351, 1982.

6 L.M. Keer and M.D. Bryant. A pitting model for rolling contact fatigue. ASME, Journal of lubrication technology, Vol. 105, , pp. 198-205, 1983.

7 J.J. Kalker. Three-dimensional elastic bodies in rolling contact. Kluwer Academic Publishers, 1990, $314 \mathrm{p}$.

8 F. Erdogan, G.D. Gupta and T.S. Cook. Numerical solution of a singular integral equation. In Method analysis and solution of crack problems. Ed. by Sih, Leyden, Nordhoff International Publishing, p. 368-425, 1973. 